\title{
USING VIRTUAL BANG-BANG CONTROLLERS TO OPTIMIZE TREATMENT OF BRAIN TUMORS
}

\author{
Mhamed Nour a, Mohammed Bougataya ${ }^{\mathrm{b}}$, Aziz Oukaira ${ }^{\mathrm{c}}$, Ahmed Lakhssassi ${ }^{\mathrm{d}}$ \\ abcd Université du Québec en Outaouais, Québec, Canada \\ Corresponding email: noumo3@uqo.ca
}

\begin{abstract}
Due to the limit of thermal controllers that a patient can tolerate and the information provided by these thermal probes at discrete points only, we need a mathematical model to simulate the heat transfer and help physician to plan the dosimetry process. In order to maximize therapeutic effects while minimizing side effects, thermal switches needed to be installed at the border between healthy and tumorous tissues. These thermal switches will send a signal to stop the heat process as soon as the temperature is exceeding a trigger.

In this paper, we propose the implementation of thermal thermostats in order to control the heating process [1-4] and to simulate heating process for the Laser Interstitial Thermal Therapy in Treatment (LITT) of brain tumors.
\end{abstract}

Keywords: Laser Interstitial Thermal Therapy in Treatment, Thermal Damage, Brain Cancer, Bio Heat Transfer Simulation, Events Interface, Thermal Sensors.

\section{Introduction}

Simulation software is used to simulate the mathematical model which use thermal conduction based on Fourier's law and constant blood perfusion. We defined the following thermal and optical properties for the brain tissue: conductivity, density, specific heat, diffusivity, relative permeability and electrical conductivity. The results will be the thermal distribution of the temperature and the volume of tissues damaged with and without the thermal switches.

Predicting the results in term of volume damage to the tissue will improve the health care system.

To interact with the physician, we build apps. As soon as the physician will enter the power and time of the treatment, the application should be smart enougth to authorize or deny the action.

\section{Materials and Methods}

\section{A. The Simulation model}

The tissue brain geometry is represented as a cylinder of $2.54 \mathrm{~cm}$ radius by $2.54 \mathrm{~cm}$ thickness, as shown in Figure 1 . The tissue is then heated up to 30 minutes by a $5 \mathrm{~W}$ laser heat source. The initial temperature of the brain tissue is $20 \mathrm{deg}$. 


\section{Asia Pacific Journal of Contemporary Education and Communication Technology \\ ISBN (eBook): 9780994365682 | ISSN : 2205-6181 \\ Year: 2017 , Volume: 3, Issue: 2}

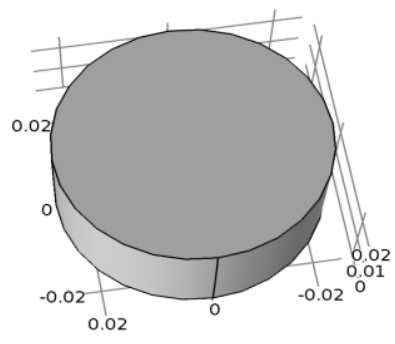

Figure 1: The tissue brain geometry is represented as a cylinder of $2.54 \mathrm{~cm}$ radius by $2.54 \mathrm{~cm}$ thickness

\section{B. Modeling of the Laser source.}

We used a build-in Gaussian Pulse functions with Gaussian profile gp1 (figure 2), to model the laser bean. It is assumed that the emissivity of the brain tissue surface is approximatively 0.8 , the absorpitivity and emissivity are equal, we also multiply the heat load by the emissivity.

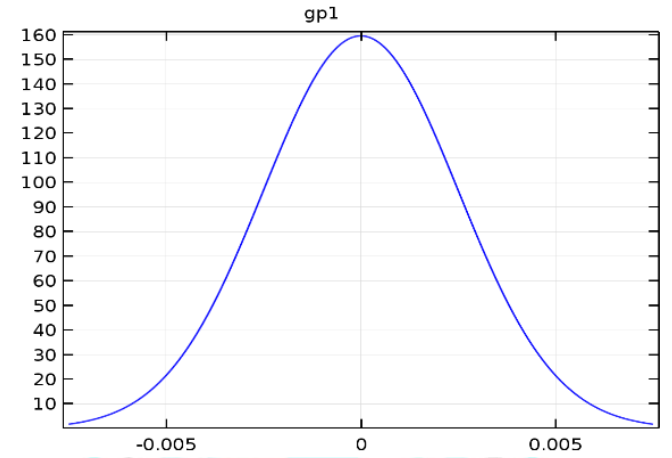

Figure 2: The function Gaussian Pulse with location o and Standard deriation equal rspot.

Wv1 represent the waveform function which is a Triangle with the following parameters:

An angular frequency $=0$;

Phase $=0$;

And the Amplitude equal 1.

The function below is an analytic heat function included within COMSOL Library (figure 3):

(1)

Where defined the source power, is Gaussian pulse function, is the waveform function and $t$ is the time.

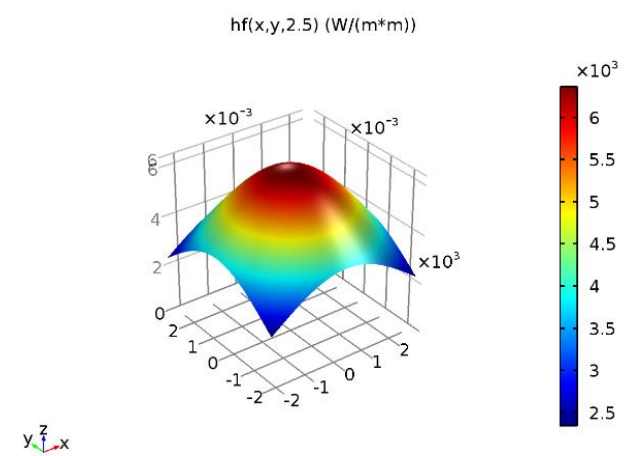

Figure 3: Analytic heat function hf. 


\section{Modeling in COMSOL Multiphysics}

\section{C.1. Geometrical description of the model}

A cylinder $2.54 \mathrm{~cm}$ radius by $2.54 \mathrm{~cm}$ thickness brain tissue is heated up to 30 minutes by a $5 \mathrm{~W}$. Temperature sensors are at the boundary of the healthy and tumorous tissues. They will interact with the heating source function in order to try do not exceed a temperature limit at the healthy tissues.

\section{C.2. Heat distribution}

Our model is modelled using the bio heat transfer with time dependent study. Tables 1 and 2 describe parameters used using our simulation.

The Heat Equation used for this simulation

$$
\begin{aligned}
& \rho C_{p} \frac{\partial T}{\partial t}+\rho C_{p} \mathbf{u} \cdot \nabla T+\nabla \mathbf{q}=Q+Q_{\text {bio }} \\
& q=-k \nabla T \\
& \mathrm{Q}=\mathrm{hf}(\mathrm{x}, \mathrm{y}, \mathrm{t}) \\
& Q_{b i o}=\rho_{b} C_{b} \omega_{b}\left(T_{b}-T\right)+Q_{\text {met }}
\end{aligned}
$$

is the heat capacity $\left.\mathrm{J} /\left(\mathrm{kg}^{*} \mathrm{~K}\right)\right)$, is the density of the brain tissue $\left(\mathrm{kg} / \mathrm{m}^{\wedge} 3\right)$, $\mathrm{T}$ is temperature $(\mathrm{K})$, $\mathrm{k}$ is the thermal conductivity of the brain tissue $\left(\left(\mathrm{W} /\left(\mathrm{m}^{*} \mathrm{~K}\right)\right)\right.$, and is the heat capacity $\left.\mathrm{J} /\left(\mathrm{kg}^{*} \mathrm{~K}\right)\right)$, is the laser source, $\mathrm{q}$ is the heat flux density, represents the perfusion, $\mathrm{T}, \mathrm{t}$, are respectively specific blood heat, blood perfusion rate, temperature, time, blood density, metabolic heat source, blood flow rate.

Table 1: Settings of QBIO parameters

\begin{tabular}{|l|l|}
\hline Description & Value \\
\hline Arterial blood temperature & $310.15[\mathrm{~K}]$ \\
\hline Specific heat, blood & $3650\left[\mathrm{~J} /\left(\mathrm{kg}^{*} \mathrm{~K}\right)\right]$ \\
\hline Blood perfusion rate & $0.866[\mathrm{l} / \mathrm{s}]$ \\
\hline Density, blood & $1035 \mathrm{~kg} / \mathrm{m}^{3}$ \\
\hline Metabolic heat source & 0 \\
\hline
\end{tabular}

We consider the fellowing initial conditions:

- $\quad \mathrm{To}=293.15 \mathrm{~K}$ is the initial temperature of the tissues.

- $\quad$ The thermo-optical parameters constant during the treatment.

- The Metabolic heat is negligible.

\section{C.3 Bang-bang Controller}

We implemented sensors [6] at the border between healthy and tumorous brain tissues. We used events interface to control the heating process, by either allowing or stopping the source function depending on a temperature limit. As soon as the thermal controller reaches the temperature limit at the border, it will send a signal to stop the heating process immediately. We defined the bang-bang controller as follows: 
$\operatorname{Tmax}=55 ;$

$\operatorname{Tmin}=45$;

$\mathrm{T} \_\mathrm{s}=\operatorname{intop} 1(\mathrm{~T})[\mathrm{K}]$;

HeaterState $=1$;

$\mathrm{Up}=\mathrm{T} \_\mathrm{s}-\mathrm{Tmax}[\operatorname{degC}]$;

Down=T_s-Tmin[degC];

If $\mathrm{Up}>\mathrm{O}$ then HeaterState $=0$;

If Down $<0$ then HeaterState $=1$

Where Tmax is the temperature limit, Tmin is the temperature minimal, $\mathrm{T} \_\mathrm{s}$ is the integral of temperature at the sensors points, HeaterState is a variable with will be 1 or $\mathrm{o}$, Up and Down are two variable controlling the HeaterState depending on the temperature of the T_s.

We then add the HeaterSate to the heat source function:

$\mathrm{Q}=\mathrm{hf}(\mathrm{x}, \mathrm{y}, \mathrm{t})^{*}$ HeaterState

The source function will include the variable HeaterState.

\section{C.4 Mesh}

The brain tissue is meshed using a triangle swept mesh as shown in Figure 4.

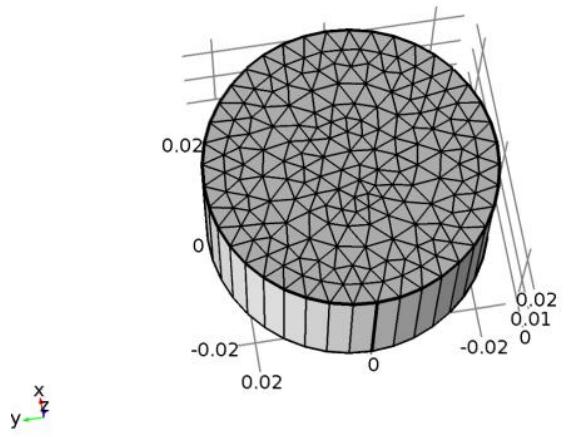

Figure 4: Result of the mesh process.

\section{C.5 Definition of the Thermal damage}

We used the first order Arrhenius equation to compute yje damage integral [7-8]:

$\Omega(\mathrm{t})=\ln \frac{\mathrm{C}_{0}}{\mathrm{C}_{\mathrm{UD}}(\mathrm{t})}=\int \operatorname{Aexp}\left[-\frac{\mathrm{E}_{\mathrm{a}}}{\mathrm{RT}(\mathrm{t})}\right]_{\mathrm{dt}}$

where $\mathrm{C}_{0}$ is the original concentration of undamaged cells, $\mathrm{C}_{\mathrm{UD}} \mathrm{C}_{\mathrm{UD}}$ is the concentration of the remaining living cells after time $t$, the treatment time, $A$ is the frequency factor, $E_{a}$ is the activation energy and $\mathrm{R}$ is the universal gas constant. $(\mathrm{R}=8.314 \mathrm{~J}$ mol-1 K-1).

A damage integral of $\Omega=1$, corresponds to $63 \%$ percent probability of cell death, and damage integral of $\Omega=4.6$, corresponds to $99 \%$ percent probability of cell death at a specific point. 
Table: Properties of brain tissue used during the simulation

\begin{tabular}{|l|l|l|l|}
\hline Name & Expression & Value & Description \\
\hline rmat & $1[\mathrm{in}]$ & $0.0254 \mathrm{~m}$ & material inner radius \\
\hline Thickness & $25400[\mathrm{um}]$ & $0.0254 \mathrm{~m}$ & mat inner thickness \\
\hline rspot & $8[\mathrm{~mm}]$ & $0.008 \mathrm{~m}$ & Radius of laser spot size \\
\hline plaser & $5[\mathrm{~W}]$ & $5 \mathrm{~W}$ & Laser power \\
\hline Period & $10[\mathrm{~s}]$ & $10 \mathrm{~s}$ & $\begin{array}{l}\text { Time of laser to move back and } \\
\text { forth }\end{array}$ \\
\hline Emissivity & 0.8 & 0.8 & surface emissivity of mat1 \\
\hline Temp & $310.15[\mathrm{~K}]$ & $310.15 \mathrm{~K}$ & Initial Temperature \\
\hline Heat Capacity & $3636\left[\mathrm{~J} /\left(\mathrm{kg}^{*} \mathrm{~K}\right)\right]$ & $3636\left[\mathrm{~J} /\left(\mathrm{kg}^{*} \mathrm{~K}\right)\right]$ & Brain Heat Capacity \\
\hline Density & $1050\left[\mathrm{~kg} / \mathrm{m}^{\wedge} 3\right]$ & $1050\left[\mathrm{~kg} / \mathrm{m}^{\wedge} 3\right]$ & Brain Density \\
\hline $\begin{array}{l}\text { Thermal } \\
\text { conductivity }\end{array}$ & $0.51\left[\mathrm{~W} /\left(\mathrm{m}^{*} \mathrm{~K}\right)\right]$ & $0.51\left[\mathrm{~W} /\left(\mathrm{m}^{*} \mathrm{~K}\right)\right]$ & Brain Thermal conductivity \\
\hline A & $7.39 \mathrm{e} 39[1 / \mathrm{s}]$ & $7.39 \mathrm{e} 39$ & Frequency factor \\
\hline dE & $2.577 \mathrm{e}[\mathrm{J} / \mathrm{mol}]$ & $2.577 \mathrm{e} 5$ & Activation energy \\
\hline
\end{tabular}

\section{Simulation Results}

During the simulation, the physician can vary the input values to control the thermal ablation during a laser surgery/cancer treatment. The question is how can the temperature sensors help control the process?

Simulation 1. We ran the simulation for 30 minutes, power source at $10 \mathrm{~W}, \mathrm{Tmax}=55$ and $\operatorname{Tmin}=45$.

Figure 5 shows the state of the heater during the simulation. The thermal switch is flipping between $\mathrm{o}$ and 1 to control the heat source.

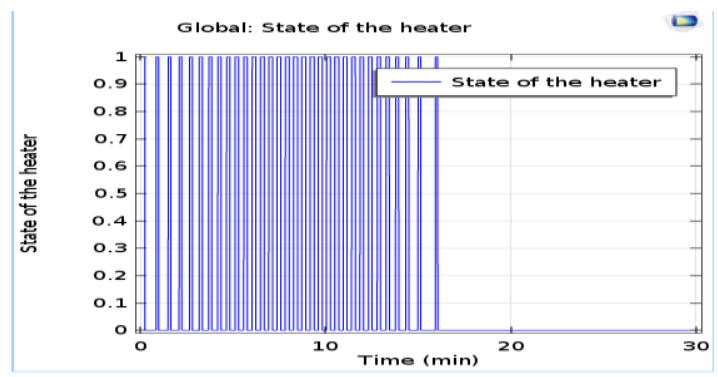

Figure 5: State of the Heater during the simulation.

Figure 6 shows the maximal temperature at the sensor points. The thermal sensor stops the heater but the healthy tissue continues to be heated exceeding $75 \operatorname{degC}$ even if the function source stopped. This is due to the fact that when heating at a great temperature, even if we stop 
the heater, the tissue will act as a new heater source. In this situation, damage will form in the healthy tissue.

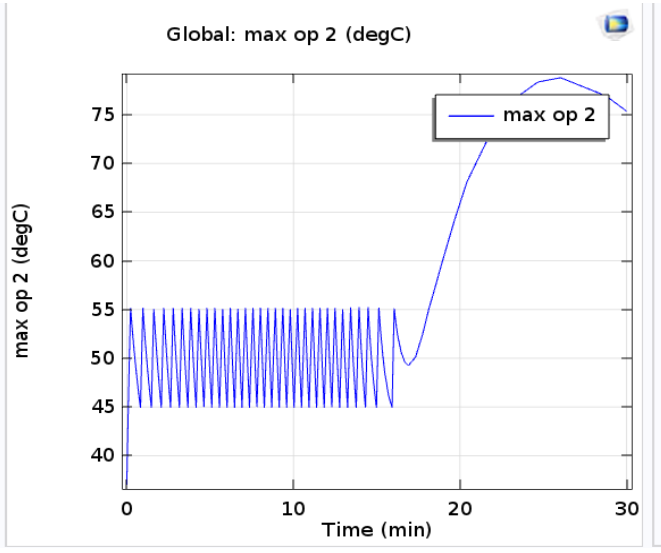

Figure 6: Maximum Temperature (degC) of the Tissue during 30 minutes at the sensor points.

Simulation 2. We ran the simulation for 30 minutes, power source at $5 \mathrm{~W}, \mathrm{Tmax}=55$ and Tmin $=45$.

Figure 7 shows the state of the heater during the simulation.

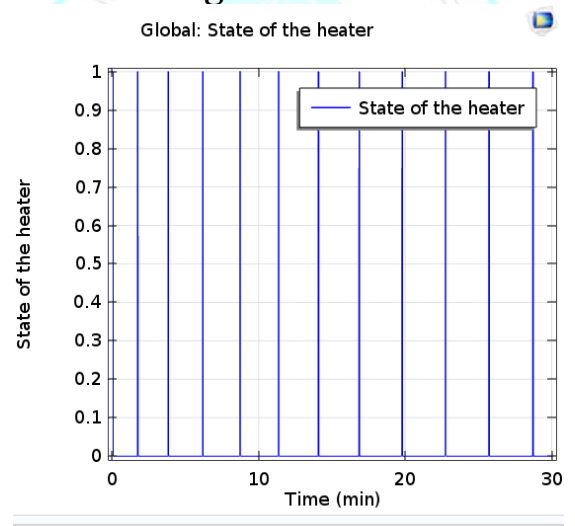

Figure 7: State of the Heater during the simulation.

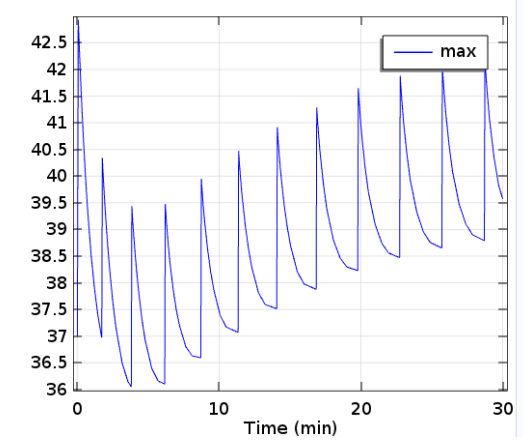

Figure 8: Maximum Temperature (degC) of the Tissue during 30 minutes at the sensor points. 
Figure 8 shows the maximal temperature at the sensor points. The thermal sensor controls the heating process and in this case, the temperature at the sensor point did not exceed Tmax.

Simulation 3. Let's keep the power and the time, but put realistic limits; Tmax $=35$ and Tmin=37. Even if the temperature sensor stopped the heating process around $10 \mathrm{~min}$, the temperature at sensor points increased.

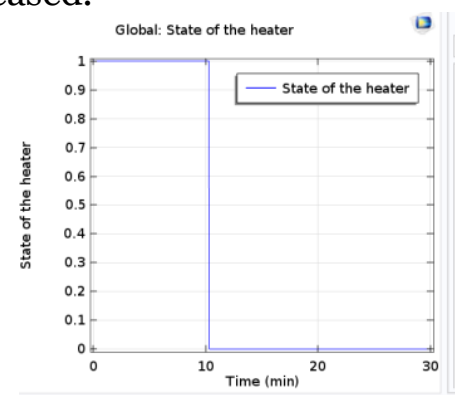

Figure 9: State of the Heater during the simulation.

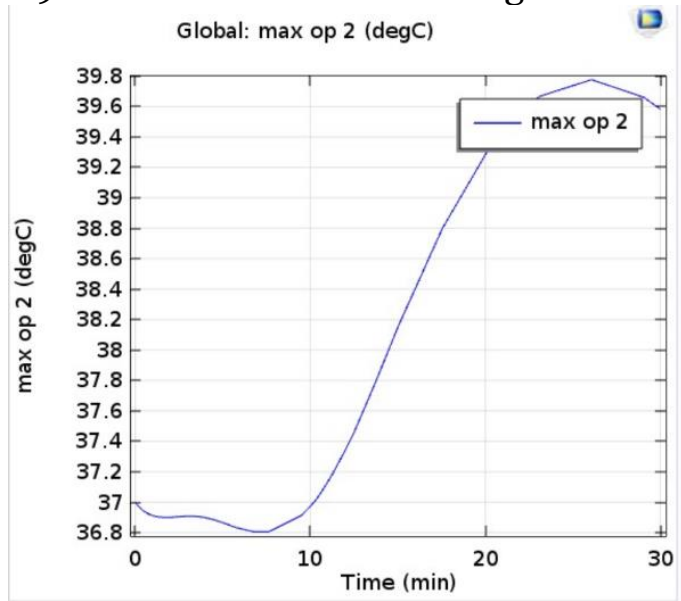

Figure 10: Maximum Temperature (degC) of the Tissue during 30 minutes at the sensor points.

Therefore, exclusively using sensor mechanisms is ineffective because even if the sensor stops the heating process, the tissue temperature will still increase due to conduction. Figure 10 shows the volume heated at temperature Tmax during 5 minutes. For instance, if the heating process was supposed to stop at 2 minutes and it did not, this figure shows the damage that would be caused to the tissue. Another system would be necessary to improve the system.

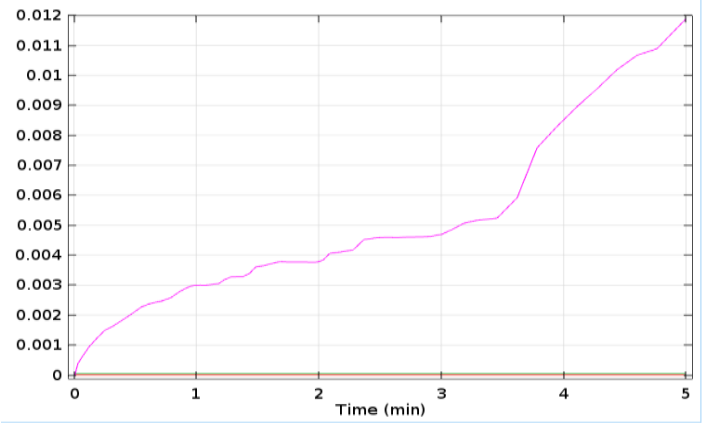

Figure 10. Tissue volume heated at temperature Tmax during 5 minutes. 


\section{VIRTUAL BANG-BANG CONTROLLER}

The idea is to introduce a new process at the heater controller. When the physician enters new values for power and time, the controller process will run a simulation. If the temperature of any sensor points exceeds Tmax; the controller will warn the physician to lower the power value, otherwise it will authorize the heating process.

Figure 11 shows one sensor (blue line) vs multiples sensors' temperature (green line). This demonstrates that we should implement sensors in the edge point of the tumor.

Global

B

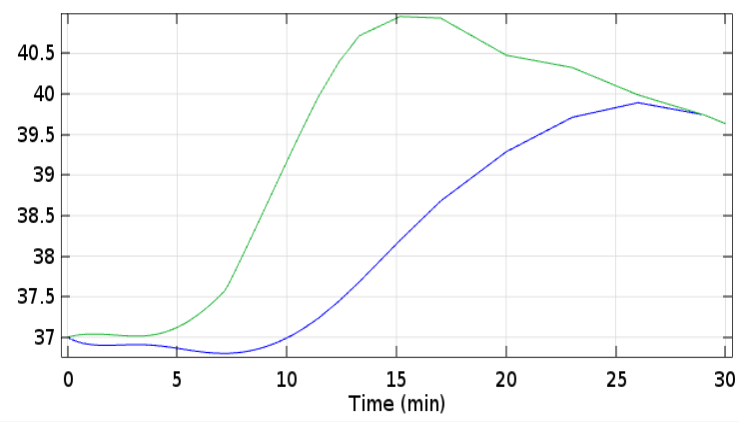

Figure 11. maximum temperature of one sensor vs multiple sensors.

An important question is, are physical thermal sensors necessary? Furthermore, how many are needed because the omission of one results in tissue damage.

The answer is that the virtual sensors are in fact necessary at all edge limit points (figure 12). These sensors will impact and stop the heat source at any time a single sensor's temperature exceeds the temperature limit. Figure 13 shows real sensors at limit edges is mandatory because we will not be to approximate the real geometry.

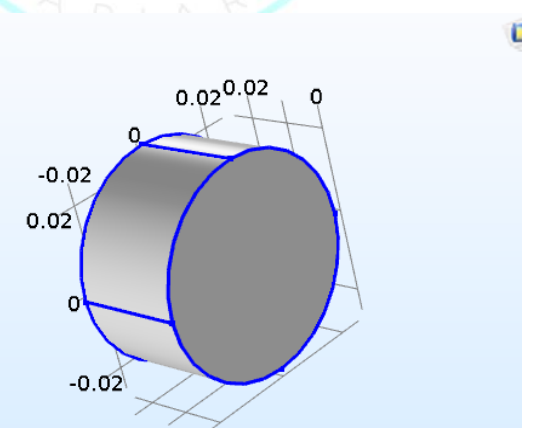

Figure 12. Multiple virtual sensors at the edge points.

We used 3D slicer to convert an MRI stack of a tumour Brain. After going through the steps; data load, volume rendering, crop volume, editor and save the output as an stl file. We used the stl file on our Comsol simulation. Figure 13 is the result of the 3D Slicer transfer from the MRI stack to stl. 


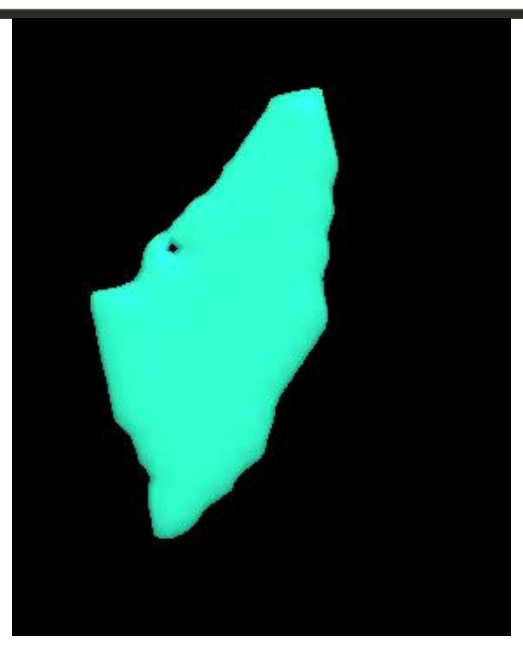

Figure 13. Real 3D brian tissue extarcted from a stack of MRI and generating stl file.

\section{Apps for Physicians use}

Using the Application Builder desktop environment, we build apps. The physicians will use the application remotely. The physician will enter the laser power, the time of the treatment, the temperatures maximal and minimum at the border between the two tissues. The system will then approve the heating process if the maximum temperature is not exceeded by any of the sensors. The system will also provide a graph of the heater state that will be used in conjunction with the power source. If the temperature of any edge limit exceeds the maximum temperature, the system will stop the treatment with a warning message. For this simulation, the laser source is at the surface of the tissue. When we apply the source inside the tissue, the physician will also enter the position of the laser source inside the tissue.

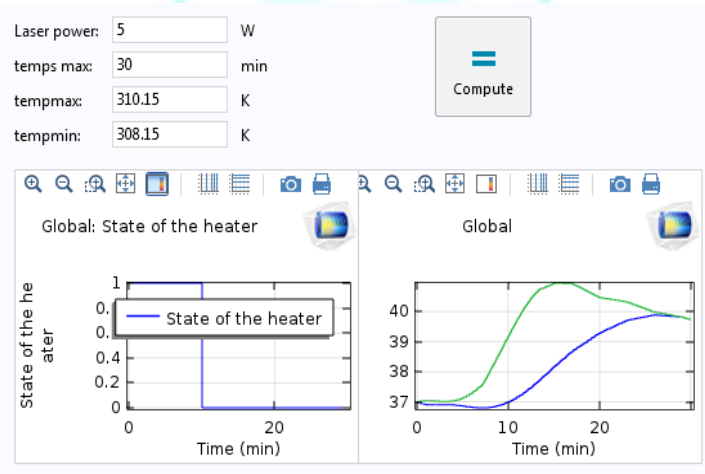

Figure 14. Output of the Apps. 


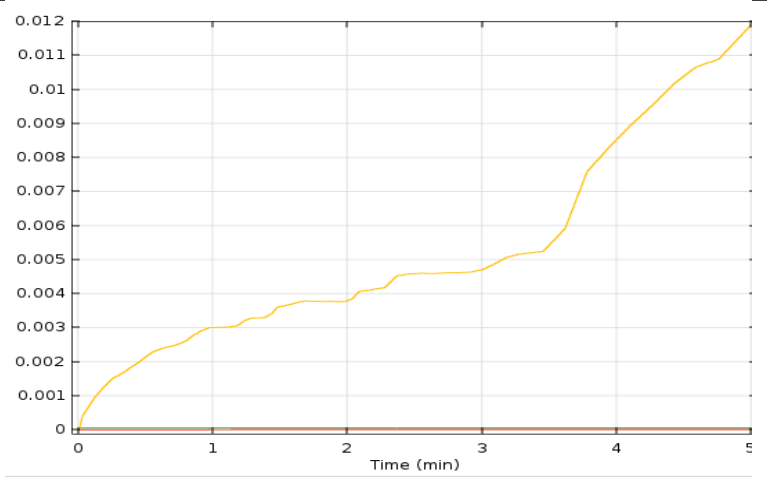

Figure 15. Volume damage per time.

\section{Conclusion}

In this paper, In order to control thermal ablation process, we proposed a model to help preventing any side effect during the laser treatment, by controlling the heating process using thermal sensors at the edge limits of the tumor tissues. The application will output the temperatures at edge limit between the two tissues.

Our next step will be to generate for a specific tissue, the dosimetry plan which will not have any side effect. This new algorithm will use the virtual bang-bang installation to predict volume damage for the dosimetry plan proposed. Figure 15 outputs the volume damage per time, which will be the input to our next step. 


\section{Asia Pacific Journal of Contemporary Education and Communication Technology \\ ISBN (eBook): 9780994365682 | ISSN : 2205-6181 \\ Year: 2017 , Volume: 3, Issue: 2}

\section{References}

i. Chen, X. \& Saidel, G. M., 2010. Modeling of Laser Coagulation of Tissue with MRI Temperature Monitoring. Journal of Biomechanical Engineering.

ii. Comsol.com, 2015. Implementing a Thermostat with the Venets Interface. [Online] Available at: https://www.comsol.com/blogs/implementing-a-thermostat-with-the-eventsinterface/ Feb 19/2015 [Accessed 19 February 2015].

iii. Mohammadi, A. M. \& Schroeder, J. L., 2014. Laser Interstitial thermal therapy in treatment of brain tumors - the Neuro Blate System, London, UK: Informa.

iv. Nour, M., Lakhssassi, A., Kengne, E. \& Bougataya, M., 2015. 3D Simulation of the Laser Interstitial Thermal Therapy in Treatment (LITT) of Brain Tumors Proceedings of the 2015 COMSOL Conference in Boston. Boston, COMSOL.

v. Singh, S. \& Repaka, R., 2015. Pre-clinical Modelling and Simulation of Hepatic Radiofrequency Ablation. Proceeding of the Comsol 2015. Conference in Pune. Pune, COMSOL.

vi. Tissue Properties Foundation, 2016. Tissue Properties Database. [Online] Available at: https://www.itis.ethz.ch/virtual-population/tissue-properties/database/heattransfer-rate/ August 12/2016 [Accessed 12 August 2016].

vii. $\quad$ Tung, M. et al., 2008. Modeling the Heating of Biological Tissue based on the Hyperbolic Heat Transfer Equation. 20 ed. Valencia: Univesdidad Politecnica de Valencia.

viii. $\quad$ Tyc, R. \& Wilson, K. J., 2010. Laser Surgery/Cancer Treatment: Real-time interactivity enhances interstitial brain tumor therapy, s.l.: Bio-Optics World. 